\title{
The perception of rhythm in language
}

\author{
Anne Cutler* \\ Max-Planck-Institut für Psycholinguistik, Wundtlaan 1, 6525 XD Nijmegen, Netherlands \\ MRC Applied Psychology Unit. Cambridge, UK
}

\section{The segmentation problem}

The orthography of English has a very simple basis for establishing where words in written texts begin and end: both before and also after every word are empty spaces and this demarcation surely helps the reader comprehend. In a spoken text, however, as presented to a hearer, such explicit segmentation cues are rarely to be found; little pauses after every single word might make things clearer, but the input is continuous - a running stream of sound. This implies that part of listening involves an operation whereby input is segmented, to be processed word by word, for we cannot hold in memory each total collocation, as most sentences we come across are previously unheard. Yet we listeners experience no sense of some dramatic act of separating input into pieces that are known; as we listen to an utterance it seems unproblematic-words in sentences seem just as clear as words that stand alone. Just how listeners accomplish such an effortless division is a question that psychologists have now begun to solve, and this paper will describe (although with minimal precision) some experimental studies showing what it might involve. The findings, as this summary explains, at once can vindicate the order of the problem and the hcarcr's sense of case, for though speech must be segmented, yet the data plainly indicate that rhythm in the input makes segmenting speech a breeze.

\section{The language specificity of rhythmic structure}

Now linguistic rhythmic structures have a noticeable feature in that languageuniversal they are definitely not. This fact is all too obvious to any hapless teacher

\footnotetext{
${ }^{*}$ Correspondence to: Anne Cutler, Max-Planck-Institut für Psycholinguistik, Wundtlaan 1, 6525 XD Nijmegen, Netherlands. E-mail anne@mpi.nl
} 
who has tried to coax the prosody of French from, say, a Scot. Thus while English rhythmic structure features alternating stresses in which syllables contrast by being either strong or weak, this particular endowment is not one which French possesses, having rather one where syllables are equal, so to speak. These distinctions were expressed within traditional phonetics as uniquely based on timing (stress or syllable), though now we admit of more complexity in rhythmic exegetics and of other types of patterning that languages allow; thus in Japanese the mora is the (subsyllabic) unit which provides the root of rhythm, as phonologists maintain. An important source of evidence, and few would dare impugn it, can be found in verse and poetry: the metrical domain. So compare the English limerick, a form which thousands take up, with the haiku, a poetic form of note in Japanese; there are five lines in a limerick, and stress defines their make-up: the third and fourth are two-stress lines, the others all are threes; and analogously haiku have their composition reckoned by the mora computation, in a manner iron-cast: while the longest line in morae, having seven, is the second, there are five and only five in both the first line and the last.

\section{The use of rhythm in listening}

Just those rhythms found in poetry are also those which function in perception, as the work referred to earlier suggests; thus for English there is evidence involving a conjunction of spontaneous performance and experimental tests, which together show that listeners use stress in segmentation, by hypothesizing boundaries when syllables are strong. Since the lexicon has far more words with strong pronunciation of the word-initial syllable, this method can't go wrong. In comparison with English we should surely not ignore a set of studies ${ }^{2}$ run quite recently on hearers in Japan, which produced results consistent with the story that the mora is the unit that these listeners segment by when they can; while those studies $^{3}$ that initiated all this lengthy series were performed on native listeners of French some years ago, and they demonstrated well beyond the range of any queries that these listeners used syllables for parsing speech en mots. More

'Cutler, A. \& Norris, D.G. (1988). The role of strong syllables in segmentation for lexical access. Journal of Experimental Psychology: Human Perception and Performance, 14, 113-121. Cutler, A., \& Butterfield. S. (1992). Rhythmic cues to speech segmentation: Evidence from juncture misperception. Journal of Memory and Language, 31, 218-236.

'Otake, T.. Hatano, G., Cutler, A.. \& Mehler, J. (1993). Mora or syllable? Speech segmentation in Japanese. Journal of Memory and Language. 32, 358-378. Cutler, A.. \& Otake, T. (submitted). Mora or phoneme? Further evidence for language-specific listening.

${ }^{3}$ Mehler, J., Dommergues, J.-Y., Frauenfelder, U., \& Segui, J. (1981). The syllable's role in speech segmentation. Journal of Verbal Learning and Verbal Behavior, 20, 298-305. Segui, J., Frauenfelder, U.H., \& Mehler, J. (1981). Phoneme monitoring, syllable monitoring and lexical access. British Journal of Psychology, 72, 471-477. 
experiments were subsequently carried out in Spanish, and in Catalan and Portuguese and Québecois and Dutch, which in spite of minor variance did nothing that would banish the conclusion that for hearers rhythm matters very much. So the picture that emerges is that rhythm as exhibited in verse forms of a language can effectively predict those procedures which, assuming that their use is not inhibited, allow us to declare the segmentation problem licked.

\section{The non-use of rhythm in reading}

Unexpected complications to this neat account, however, are observed when we consider rhythms found in written text. Some preliminary findings, which this section will endeavour to elucidate, at first left their discoverer perplexed. For if rhythm is so integral a part of our audition, then it ought to be the case that it is hard to overlook; but the most pronounced of rhythms can escape our recognition when they're reproduced in printing in an article or book. Late in 1989 the present author wrote a letter, in which verse (or rather, doggerel) pretended to be prose, to at least a hundred friends, from whom responses showed the better part had not perceived the rhymes at all, wherever they arose. In a follow-up, a colleague ${ }^{4}$ gave this ready-made material to subjects to read out, and his results were even worse: of the readers who produced the text, in strict progression serial, not one perceived the letter as a rhyming piece of verse. But the selfsame text, however, may be printed as a ballad (thus, with lines which end in rhymes), and any reader can descry where the rhythm is, which renders this interpretation valid: written rhythm's only noticed when it clearly hits the eye. But perhaps the readers' lack of use of rhythm, as conceded, if judiciously considered has a lesson it can teach: it arises just because no segmentation step is needed. Thus the role of language rhythm is in understanding speech.

\footnotetext{
${ }^{4}$ Many thanks to Aki Fukushima and Bob Ladd for conducting this study and permitting me to describe it.
} 